\title{
Describing a Clinical Group Coding Method for Identifying Competencies in an Allied Health Single Session
}

\author{
Shelley L Craig $\mathbb{D}^{1}$ \\ Lauren B Mclnroy (iD ${ }^{2}$ \\ Andrew D Eaton (iD ${ }^{3}$ \\ 'Factor-Inwentash Faculty of Social Work \\ (FIFSW) at the University of Toronto, \\ Toronto, ON M5SIV4, Canada; ${ }^{2}$ College \\ of Social Work at the Ohio State \\ University, Columbus, OH 43210, USA; \\ ${ }^{3}$ FIFSW at the University of Toronto, \\ Toronto, ON M5SIV4, Canada
}

This article was published in the following Dove Press journal: Journal of Multidisciplinary Healthcare

Introduction: Competencies that integrate research findings and practice expertise are necessary to maintain comprehensive evidence-based practice for allied health professions, such as social work. The context of modern multidisciplinary healthcare, especially in acute or emergency settings, means that an individual clinician may only have a single session with a patient. Maximizing the benefit of single sessions requires advanced competence that extends beyond diagnostics and biomedical treatments to the impact of social systems on health outcomes; multilevel advocacy for reduction of existing health disparities and equity in access to health and mental health services; and "working knowledge" of non-pharmacological treatments.

Methods: This study employed a practice-based research methodology whereby health social workers group coded 32 simulation videos, drawn from an advanced social work practice course, to develop a practice-based competency framework that incorporates these advanced skills. Constructivist grounded theory was employed through a cyclical coding process of viewing video data, identifying and discussing skills and competencies, and summarizing/synthesizing the discussions for critical reflection.

Results: The resulting Clinician Group Coding Method utilized systematic and collaborative group coding of practice simulation videos by three clinicians and two researchers to identify relevant competencies for a single session. Emphasis was placed on the progressive phases of single-session patient interactions (eg, joining, working, ending), a practice format that frequently occurs in social work and other allied health professions. These phases include themes of preparing, agenda setting and refining, addressing context, providing education, planning the next steps, and encouraging success.

Discussion: The group coding process allowed for immediate discussions and clarifications, supporting the clinicians to synthesize their experiences toward shared understandings of "best practices" in single-session healthcare contexts. This approach facilitated the understanding of critical actions that allied health clinicians could undertake to improve singlesession interactions. This practice-based competency framework may have significant utility for multidisciplinary healthcare education and practice.

Keywords: simulation, practice-based research, competence, allied health, group coding, education

\section{Background}

Effective practice from allied health clinicians (eg, social workers, psychologists, occupational therapists) in health and mental health settings necessitates the identification of practice competencies. Extant research on clinician competence has found that best practices include being cognizant, communicative, innovative,
Factor-Inwentash Faculty of Social Work

(FIFSW) at the University of Toronto,

Toronto, ON M5SIV4, Canada

$\mathrm{Tel}+|4| 6-978-8847$

$\mathrm{Fax}+1416-978-7072$

Email shelley.craig@utoronto.ca
Journal of Multidisciplinary Healthcare 2020:13 | |33-||42 
introspective, holistic in incorporating information from multiple sources (eg, clinicians, patients, families), and evidence-driven. ${ }^{1-3}$ In this context, being evidence-driven ideally integrates knowledge from both rigorous empirical research and real-world, practice-based research (PBR), resulting in comprehensive evidence-based practice (EBP). ${ }^{4}$ EBP is an evolving concept in the health professions. ${ }^{5}$ It has been described as

The conscientious, explicit, and judicious use of current best evidence in making decisions about the care of individual patients ... integrating individual clinical expertise with the best available external clinical evidence from systematic research. ${ }^{6}$

Conceptualization of EBP as an ongoing process incorporating research, clinicians' expertise, and patients' values has received support for its responsiveness to the realities of contemporary practice environments. ${ }^{5}$

EBP has significant knowledge to gain from $\mathrm{PBR} .{ }^{5,7} \mathrm{PBR}$ involves investigation grounded in actual practice (rather than solely in academia), resulting in research findings reflective of and useful to those practice environments. PBR also promotes collaborative networks and partnerships between allied health clinicians and researchers, facilitating a crucial shift in power and responsibilities in the research process that permits clinicians to generate and implement research emerging from practice. ${ }^{5,7}$ PBR is proposed to provide practicebased solutions and improve services for patients and families. ${ }^{7}$ Both EBP and PBR are effective in informing education and practice competencies and are quite compatible when used purposefully. ${ }^{5,7}$ The emphasis on integrating the realities of the practice environment, rigorous research, and quality education is focused on improving patients' health and mental health outcomes. ${ }^{8}$ For example, balancing high patient volumes with patient needs in hospital acute and emergency departments can mean that multidisciplinary allied healthcare clinicians may only have a single session with a patient.

\section{Competencies in Allied Healthcare}

Allied health competencies are a set of knowledge, skills, attitudes, and values evident in professional behavior., ${ }^{9,10}$ For example, the Canadian Centre on Substance Abuse (2007) defines competencies across disciplines as measurable specific knowledge and skills required to effectively perform a particular job function or role. ${ }^{11}$ Competence focuses on what clinicians or clinicians-in-training (ie, students) are able to demonstrate in practice (ie, technical skills), as opposed to what they know (ie, academic knowledge). ${ }^{12}$ While competency-based education and training is embraced by some allied health disciplines, such as nursing and medicine, the incorporation into other allied health professions, such as social work ${ }^{13}$ has emerged more gradually. For some professions, "activities and standards of practice are easily defined, articulated and behaviourally measurable". ${ }^{14}$ This is not always the case for social work, as "complex critical thinking [and] professional values and attitudes, which are essential in social work, are [oftentimes] difficult to measure". ${ }^{14}$ As such, a framework for single-session practice competencies would be useful for social workers to further develop their skills and contributions to multidisciplinary teams. Experienced allied health clinicians are expected to further their professional competencies, ${ }^{2}$ many of which are shared across disciplines. ${ }^{15,16}$ Allied clinician activities in single sessions often include: conducting psychosocial assessments and interventions; providing supportive counseling for adjustment to illness; promoting health; and providing resources and referrals. ${ }^{17-19}$ Maximizing the benefit of this single session also requires advanced competence that extends beyond diagnostics and biomedical treatments to the impact of social systems on health outcomes; multi-level advocacy for reduction of existing health disparities and equity in access to health and mental health services; and "working knowledge" of non-pharmacological treatments. ${ }^{17,18,20}$ However, competencies for single session allied healthcare have not yet been empirically examined, and research on allied healthcare has primarily focused on team dynamics instead of direct practice with patients and their families. ${ }^{2,15}$

\section{Simulation for Allied Health Education}

Due to the increased focus in the health professions on competency-based training and the pressures of the modern medical environment, single-session competencies may be best assessed through clinician observation. ${ }^{8,21,22}$ Recorded simulation (ie, recording of structured role-plays with trained actors as standardized patients) is a particularly effective means of clinician observation. As an education tool, it allows for both active (ie, in the moment) and reflective (ie, watching recordings) observation and assessment of a learner's understanding of the material and practice competencies. ${ }^{10,23,24}$ Observing and assessing students and clinicians while they are involved in simulated practice is the most authentic way of evaluating ability, including their proficiency in performing contextually applicable social work competencies. ${ }^{1,23,25}$ In social 
work education, the use of "simulation scenarios" which imitate real-life professional/field experiences in the classroom context for the purpose of teaching skills and competencies, allow for controlled, systematic, and observable (often recorded) interactions between student social workers and simulated patients in a low-risk setting. The format also allows for debriefing, where instructors and students provide feedback, and for student self-assessment and reflection. ${ }^{9,12}$

Simulation should be integrated into educational and practice contexts in which competency frameworks are being employed, to ensure the effectiveness of such learning opportunities. Simulation scenarios need to be aligned with measurable educational outcomes evaluating student performance, including the proficient utilization of key competencies in practice. ${ }^{9,12}$ Extant research using simulation to observe clinical practice has identified a variety of general practice competencies, including meaning, duration of contact, observer perspective, feedback, personal style, use of self, translation of practice to theory, and technique. $^{26,27}$ However, an observational study of simulation to develop competencies for single session allied healthcare has not been conducted. Therefore, the purpose of this study was to develop a description of generalized practice competencies for single session allied healthcare through an innovative methodology consisting of group coding of simulation video by field-based expert clinicians. While this study focused on social work, overlapping activities in allied health mean that its framework may be applicable to other clinical professions. Thus, this paper aims to describe: (1) a framework for methodologically rigorous practice-based group coding of simulation video, (2) a collaborative PBR research model bringing together healthcare clinicians and academics, and (3) emergent practice competencies for single-session patient interaction scenarios.

\section{Coding Video Simulation Data to Identify Competencies}

The use of video data has increased in recent decades in numerous disciplines. It is employed in qualitative analyses for many purposes, such as generating narratives, recording interactions, and capturing practices. Approaches to coding video data are varied, including developing coding frameworks inductively through close analysis of the data. ${ }^{28}$ Video facilitates experimental analyses as well as the involvement of multiple parties (eg, researchers, learners) in a "community of inquiry by using tools for shared commentary". ${ }^{28}$ Video has been used previously when implementing simulation scenarios for research and educational purposes, including in analysis of simulation scenarios and debriefings. ${ }^{29,30}$ Grounded theory (GT) may be the ideal method of coding video simulation data. An inductive form of qualitative analysis, GT is a flexible yet simultaneously focused and systematic set of principles and guidelines for reciprocal data collection and analysis, which generates a theory of a particular phenomenon rooted in the data. ${ }^{31,32}$ Despite these innovative approaches, a paucity of research uses GT analysis of video data for group coding and utilizes PBR with expert allied health clinicians to develop practice competencies.

\section{Methods}

This study used video data from a simulation scenario implemented in multiple iterations of a Master of Social Work (MSW) health practice course at the University of Toronto in Ontario, Canada. The scenario was comprised of a multi-generational family (played by three paid actors) being interviewed for the first time by a social worker in a hospital setting following the diagnosis of Adolescent Type 2 Diabetes. The development and implementation of the simulation scenario are fully described elsewhere. ${ }^{12}$ During the simulation scenario, several students (all second-year or advanced-standing MSW students) took on the role of the allied health clinician. In addition to the instructor and other students in the course, an experienced clinician was present to provide students with feedback. The students were able to pause at any time and seek feedback and suggestions from the expert clinician or their peers. This ongoing debriefing process was also video recorded.

The video data of these simulation scenarios comprised approximately 10 hours of 32 simulations (each 18-20 minutes in length), and were used as secondary data to determine competencies for an allied health single session. This was accomplished by a coding team of: (1) three clinicians (none of whom were the clinician present during the simulations) and (2) two academics. The coding team collectively reviewed and analyzed parts of the video recordings in a series of data coding meetings. Three meetings, each approximately 3 hours in duration, were held. This group coding approach is unique, allowing for the combination of expert clinicians and experienced researchers/educators to generate an eventual theory about the multiple dimensions of competence in single 
session allied healthcare to guide the integration of teaching and simulation.

\section{Recruitment and Inclusion Criteria}

The academics were the study's principal investigator and the research coordinator. The clinicians were recruited through a flyer distributed through the principal investigator's network of health social workers and the social work supervisors list managed by the school of social work that hosted this study. Clinicians were required to: (1) have a Bachelor and/or Master of Social Work degree; (2) be currently working in a direct practice healthcare role; (3) have a range of practice experience (more than two direct practice jobs in health settings); (4) have worked at least 5 years in the field; and (5) have expressed interest in participation in the development of competencies. The clinicians were asked to volunteer their time. This study was approved by the University of Toronto's Health Science Research Ethics Board (Protocol ID\# 30419). The actors and students who participated in the recorded simulation scenarios, as well as the clinicians who participated in the analysis, complied with written informed consent procedures.

\section{Procedure}

Analysis by the coding team occurred over 4 months in 2015. Video analysis employing a grounded theory (GT) approach was chosen for this study due to its potential for an in-depth analysis, which can be achieved through multiple viewings compared to a live simulation. ${ }^{28}$ The Clinician Group Coding Method (Figure 1) was developed by the Coding Team to effectively manage the robust amount of video data and followed a specific sequence. To facilitate clinician engagement within a limited timeframe, the first two authors reviewed the video and identified the least useful sections (eg, set-up, not following directions), which were not shown to the coding team. The simulation scenario videos were played on a large screen for the coding team in increments of approximately $5 \mathrm{~min}$. Before the videos were played, the coding team was instructed to code for the underpinning skills and behaviours that constitute a competency or to identify a

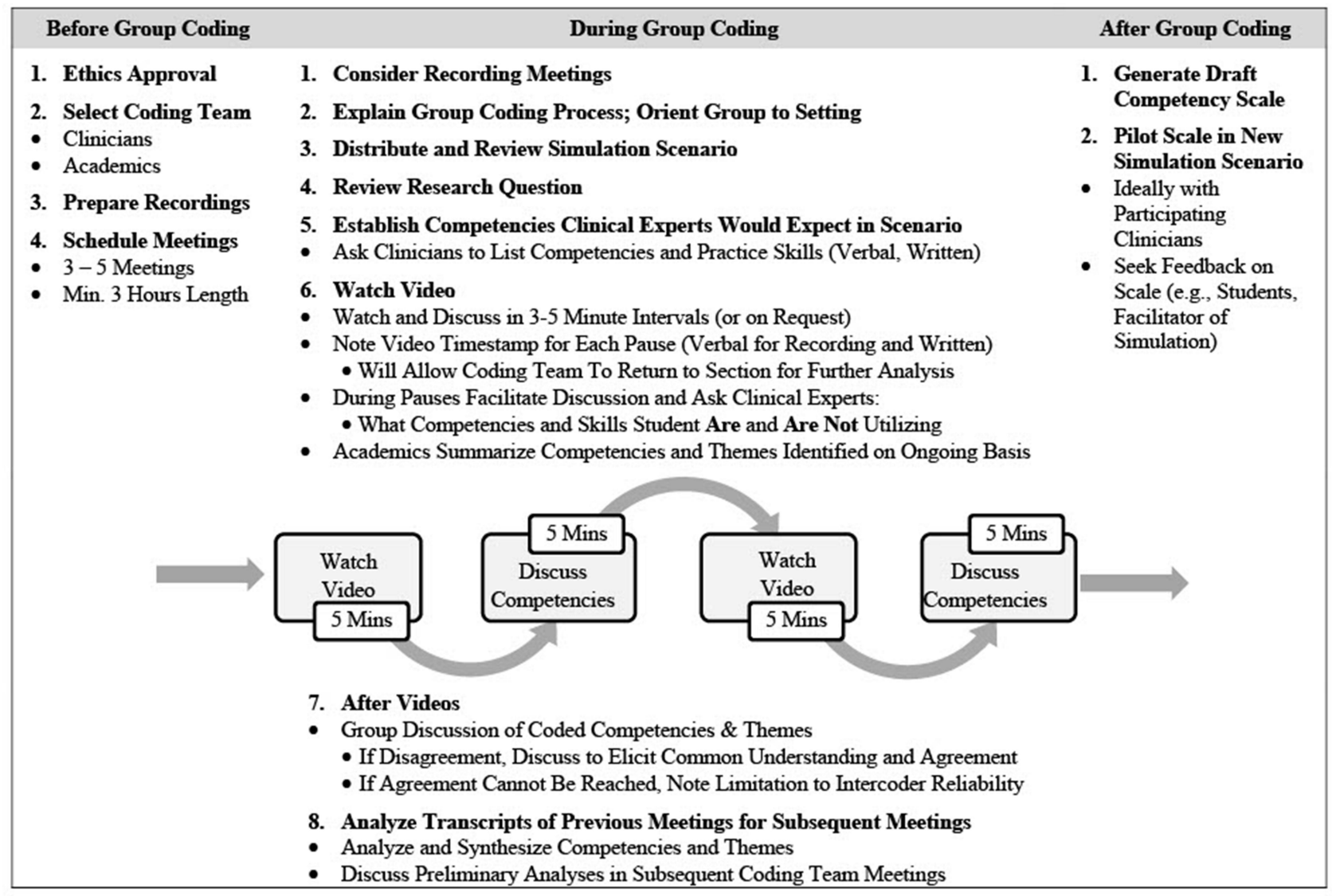

Figure I Clinician group coding method. 
competency directly via the following steps. Step one: During viewing, the coding team was encouraged to write individual notes. These notes formed the initial independent codes and were retained following each coding session as an additional data source. Step two: After each five-minute increment, the initial individual codes arising from the simulation content viewed were discussed by the group, concentrating first on practice skills utilized (or not utilized) by the students, as well as relevant tasks completed (or not completed). Each code was discussed, with discussion in most instances leading to an agreementthough wording in initial note-taking frequently varied slightly. When disagreements and coding discrepancies arose, these were resolved through focused discussions for intercoder agreement. Step three: After the initial codes were determined and discussed, meeting content subsequently focused on the development of a theoretical structure about the integration of those skills into a competency framework for single session allied healthcare. As the meetings progressed, these codes were organized into competencies of joining, working, and ending, described in more detail below.

These discussions continued over the three meetings until all the selected simulation vignettes were viewed at least once (with several viewed multiple times). Discussions were facilitated by the first author, with the second author assisting in facilitation and observation (including note-taking). Researchers and practitioners all participated in the coding team meetings by coding the simulation content and discussing their findings with regards to the emerging framework. During these coding discussions, the researchers intentionally prompted initial discussions, but encouraged the practitioners to lead the discussion and draw on their extensive practice histories. The initial codes suggested by practitioners then provided fodder for thoughtful group discussion. Researchers would subsequently suggest their codes, particularly if they had not been brought up by the practitioners. Meetings were audio-recorded and transcribed so the discussion could be synthesized and discussed at subsequent meetings.

\section{Results}

A thematic framework was generated in which the emergent key competencies of allied healthcare practice in a single session were identified and organized primarily into the three overlapping phases of a clinical consultation: (1) joining; (2) working; and (3) ending. ${ }^{33}$ See
Table 1 for the full Thematic Competency Framework. The joining phase represents the initial clinical contact with the patient (and often the family as well). The competency themes identified as primarily taking place during the joining phase were (1) preparation, introduction and purpose of meeting; and (2) setting the agenda. Codes related to these competency themes included health literacy, acknowledge new situation, clarify clinician's role, and explore patient(s) goals and reasons for being there. The working phase represents the middle part of clinical contact with the patient where the clinician is building therapeutic rapport, deepening the relationship, and supporting the patient and family unit forward with an eye toward discharge or follow-up planning. The competency themes identified as primarily occurring during the working phase were: (1) refining and carrying out the agenda; (2) addressing context and dynamics; and (3) providing education. Codes related to these themes included keeping a focus on the patient (in context), conversation with a purpose (stay on track), apply an appropriate approach for context, acknowledge the clinician's role within the larger team, provide relevant information, and solicit and respond to patient concerns. The ending phase represents the final part of clinical contact with the patient, where the clinician is ending the clinical relationship for planning and next steps, such as discharge with a goal and a post-discharge plan. The competency themes identified as most relevant for the ending phase were: (1) planning next steps; and (2) encouraging success. Codes related to these themes included summarize a plan, build towards a positive outcome, reinforce common goals (eg, patient's health), and make issues seem manageable. There was a final category of ongoing competency themes which were relevant across the three phases of the clinical consultation: (1) use of self; and (2) social work scope.

The competency themes identified throughout the process of analysis represent key indicators of competence (ie, key tasks and skills) necessary for allied healthcare practice in single-session patient interactions. Nine competency themes were generated in all, two for joining, three for working, two for ending, and two for ongoing work. The thematic competency framework is presented in Table 1. The framework outlines: (1) the phases of consultation, (2) the themes identified throughout the analysis, (3) the codes generated (ie, skills and tasks identified), and (4) sample quotes from the group analysis. Importantly, 
Table I Thematic Framework of Competencies in Single-Session Healthcare

\begin{tabular}{|c|c|c|c|}
\hline \multirow[t]{2}{*}{ Joining } & $\begin{array}{l}\text { Competency } \\
\text { Preparation, } \\
\text { introduction, and } \\
\text { purpose of } \\
\text { meeting }\end{array}$ & $\begin{array}{l}\text { Codes (Skills and Tasks) } \\
\text { Know the case and details before meeting; physical set-up of room; health } \\
\text { literacy; inclusion and language use; proximity and body language of } \\
\text { individuals involved; observe family dynamics; acknowledge new situation, } \\
\text { potential challenges; start with patient (engage youth; establish } \\
\text { relationship; build rapport); encourage coming together for common goal }\end{array}$ & $\begin{array}{l}\text { Sample Quotes from Group Coding Sessions } \\
\text { In terms of body language ... we always talk about bringing in a } \\
\text { chair and make sure you are at the patient's level rather than } \\
\text { standing over and talking over because it implies power over... in } \\
\text { an ambulatory setting it's very different } \\
\text { [patients] want to know why you are there and what your role is } \\
\text { specifically. } \\
\text { The clinician [should] start from the general to move down to the } \\
\text { specific, like [start with] a general statement around the diagnosis. }\end{array}$ \\
\hline & Setting the agenda & $\begin{array}{l}\text { Explore understanding issues and purpose of meeting; clarify clinician's } \\
\text { role; explore patient(s) goals and reasons for being there; balance } \\
\text { between agenda setting and observation; be aware of and address } \\
\text { underlying tension }\end{array}$ & $\begin{array}{l}\text { If we think methodically around the process, if there was some } \\
\text { introduction describing [the clinician's] role and then saying, "I want } \\
\text { to set the agenda together to see what we are going to talk about } \\
\text { today and I want to know what's important to you so we can talk } \\
\text { together." } \\
\text { That delicate balance that you are talking about is hard for students, } \\
\text { and for a lot of clinicians, about where [the patient] is setting the } \\
\text { agenda where I am supposed to set the agenda. } \\
\text { It's speaking to the conflict and speaking to what you are seeing; } \\
\text { [not] allowing that to continue to overwhelm a meeting where the } \\
\text { goal and objective is ... about health and instruction and new } \\
\text { diagnosis - I just speak to the tension. }\end{array}$ \\
\hline \multirow[t]{2}{*}{ Working } & $\begin{array}{l}\text { Refining and } \\
\text { carrying out the } \\
\text { agenda }\end{array}$ & $\begin{array}{l}\text { Setting ground rules; keep focus on patient (in context); bridge } \\
\text { expectation gap (patient expectations vs situational realities); } \\
\text { conversation with a purpose (stay on track); help identify and redirect to } \\
\text { common goal; time management vs ensuring patients return; rephrase/ } \\
\text { reframe; probe into underlying tensions and emotions }\end{array}$ & $\begin{array}{l}\text { I say that all the time with families who present already to staff with } \\
\text { a little tension and conflict. "We are not going to be speaking over } \\
\text { each other. One person speaks at a time." There is formalization of } \\
\text { how the communication is going to occur, which you recognize } \\
\text { based on some small details. } \\
\text { There has been no direct discussion with the youth around how } \\
\text { she feels... her body language seems disconnected from everything } \\
\text { going on. Perhaps bringing that up and acknowledging ... [giving } \\
\text { her] a chance to discuss how she's feeling around being there today } \\
\text { and engaging in this process. } \\
\text { The bridging/balancing patient versus clinician needs, expectations } \\
\text { and goals is part of moving through the agenda as the exploration of } \\
\text { what are we here to achieve today and what am I hoping to support } \\
\text { you with. A lot of students thinking about their own goals that they } \\
\text { miss a whole big part of it ... if we position it with a patient and } \\
\text { their family that you are a partner in this process and how can we } \\
\text { activate [the patient]to be a partner for her health management? } \\
\text { A lot of professionals have difficultly in engaging in conversations } \\
\text { with a purpose with patients and that's often the challenge is how } \\
\text { do you bring people back. How do you navigate this conflict that's } \\
\text { happening to this multigenerational health issue? How do you } \\
\text { bridge that? We are here for [the patient], but look ... We have } \\
\text { these two key people in her life here as well. }\end{array}$ \\
\hline & $\begin{array}{l}\text { Addressing the } \\
\text { context and } \\
\text { dynamics }\end{array}$ & $\begin{array}{l}\text { Appropriate approach for context; acknowledge power dynamics; cultural } \\
\text { awareness; tune in to patient/family; acknowledge concerns; validate } \\
\text { diagnosis as a family issue; recognize impact of diagnosis; focus on and } \\
\text { reinforce strengths; identify expectations in healthcare; acknowledge } \\
\text { clinician role in larger team }\end{array}$ & $\begin{array}{l}\text { It's important for the mother to know that ... [the teen patient's } \\
\text { experience of] diabetes does not have to replicate ... the } \\
\text { grandmother's diabetes. It is important to ask what does the } \\
\text { disease mean to you? } \\
\text { Allowing the process to unfold, initially observing some of the } \\
\text { dynamics [means] you have a lot of good information .... it's not a } \\
\text { reflection about the clinician [that the family's arguing], it's about } \\
\text { what the family need to discuss or demonstrate for you to } \\
\text { understand the context of their lives better. } \\
\text { The clinician is not solely responsible for [the patient's] care or } \\
\text { information and education to the family, and I think telling patients } \\
\text { who the team is and is important ... She said "the diabetic team" or } \\
\text { something about team [that's important]. }\end{array}$ \\
\hline
\end{tabular}

(Continued) 
Table I (Continued).

\begin{tabular}{|c|c|c|c|}
\hline Phases & $\begin{array}{l}\text { Competency } \\
\text { Providing } \\
\text { education }\end{array}$ & $\begin{array}{l}\text { Codes (Skills and Tasks) } \\
\text { Provide relevant information; enhance patient/family understanding; solicit } \\
\text { and respond to patient concerns; support autonomy; generate plan }\end{array}$ & $\begin{array}{l}\text { Sample Quotes from Group Coding Sessions } \\
\text { I am hearing about all this food business and diabetes, and there is } \\
\text { also a piece around self autonomy and deciding what you want to } \\
\text { do with your body and understanding the risks and benefits of } \\
\text { whatever is being proposed. } \\
\text { When I think of psychosocial education, I think of [talking] about in } \\
\text { general terms what the impact of this diagnosis would be on a } \\
\text { family, how it might affect relationships, normalization of some of } \\
\text { the tensions, normalizations of the grief that might come up, that's } \\
\text { more psychosocial education. Also, related to developmental stage, } \\
\text { what you might expect from a I6 year old given this new diagnosis } \\
\text { in the context of family relationships being an adolescent, in the } \\
\text { context of peers at school. } \\
\text { "Let's talk about diabetes in general. You may have a different } \\
\text { understanding." I think the sequence is important but if you hear } \\
\text { one of the family members saying something, that's when you } \\
\text { capitalize on the opportunity to interject, to provide clarity, to } \\
\text { provide education. }\end{array}$ \\
\hline \multirow[t]{2}{*}{ Ending } & $\begin{array}{l}\text { Planning and next } \\
\text { steps }\end{array}$ & $\begin{array}{l}\text { Summarize plan; provide resources; build towards positive outcome; } \\
\text { ensure understanding }\end{array}$ & $\begin{array}{l}\text { Encourage hope because I think they are very sad, grief stricken } \\
\text { about this. Very monumental and that's normal. There is also an } \\
\text { opportunity to try and instill and promote some hope that lots of } \\
\text { people do live with diabetes and a lot of people do not get } \\
\text { complications. That educational piece. } \\
\text { There was no what's the next step and even worse the family said, } \\
\text { "I am not clear on the plan." }\end{array}$ \\
\hline & $\begin{array}{l}\text { Encouraging } \\
\text { success }\end{array}$ & $\begin{array}{l}\text { Provide direction; acknowledge family's strengths; reinforce common goal } \\
\text { (patient's health); make issue seem manageable }\end{array}$ & $\begin{array}{l}\text { She was acknowledging and validating, especially of the mom and } \\
\text { the grandma and some of the stresses. The strengths she talked } \\
\text { about what I mentioned before, they are two mothers and they } \\
\text { both care for her and they want her to be healthy. The patient, not } \\
\text { as much in my opinion. } \\
\text { [The clinician] said, "You are lucky to have these lucky ladies with } \\
\text { you and supporting you." She reinforced the strength and maybe } \\
\text { support of the family }\end{array}$ \\
\hline \multirow[t]{2}{*}{ Ongoing } & Use of self & $\begin{array}{l}\text { Clinician self-awareness and self-reflexivity; stay present; critical thinking; } \\
\text { implicate self; work collaboratively }\end{array}$ & $\begin{array}{l}\text { With a lot of students that they live so much in their head thinking } \\
\text { up what they have to accomplish in this situation that they miss } \\
\text { what's happening, the observation piece. } \\
\text { There is a preparation skill set that needs to be incorporated into } \\
\text { self-reflection. The clinician needs to get into a mindset: "What am } \\
\text { I going in to do? What's going to be my approach? Do I know this } \\
\text { family? Do I know this patient? What's the context? What are the } \\
\text { key areas and the key questions that I want to address in this } \\
\text { interview?" It's that self-reflective piece that hopefully they practice } \\
\text { in the field. }\end{array}$ \\
\hline & Scope of practice & $\begin{array}{l}\text { Boundaries; degree (msw, msc); multiple theoretical perspectives; } \\
\text { scope of care (role of profession in context); continuum of care }\end{array}$ & $\begin{array}{l}\text { People do need to push themselves in a healthcare environment. It's } \\
\text { not easy. You need to be on the ball. You only have a certain } \\
\text { amount of time ... just get in there and do what you need to do. } \\
\text { We are the specialists in addressing psychosocial stressors around } \\
\text { disease. }\end{array}$ \\
\hline
\end{tabular}

many themes overlapped and are expected to play out across multiple phases of the clinical consultation.

\section{Discussion}

The process of developing standards for education and training in allied healthcare may be as critical as the actual standards that are the outcome of that process. ${ }^{8,34}$ This study illustrates the power of PBR to generate competencies for single session allied healthcare practice, which are grounded in the realities of practice environments and single-session patient interactions. This study also adds to the conceptualization of EBP, as the innovative Clinician Group Coding Method (Figure 1) incorporated elements of both rigorous empirical research and expert 
clinician knowledge in a focused approach that linked the resulting framework of competencies to the realities of contemporary service provision. ${ }^{5}$ The competencies identified and the framework developed have significant potential utility for ensuring that allied health students and emerging clinicians are adequately prepared to contend with the actualities of healthcare practice.

\section{Implications for Allied Health Research}

The Clinician Group Coding Method is a notable research innovation developed through this study, which has significant potential for application to research for other allied health practice formats, such as interdisciplinary care meetings with patients, as well as a limitless variety of allied health and discipline-specific research projects into practice competencies. The methodological approach of employing practicing clinicians for collaborative group coding of video recordings of practice scenarios to identify relevant competencies may be applicable to projects that seek to identify critical skills in a particular practice setting through the "clinician lens."

The Clinician Group Coding Method also has several additional strengths. For example, the utilization of the simulation videos in this study allowed the clinicians to precisely identify competencies more immediately and objectively instead of attempting to recall previous practice experiences and observations of students. The collaborative nature of the coding process which allowed for immediate discussions and clarifications and also encouraged the clinicians to extend their own professional perspectives toward shared understandings of "best practices" in single-session healthcare. This approach encouraged understanding of critical decisions and actions (eg, clinical pathways) that students training for an allied health profession should undertake during single-session interactions. $^{23}$ The collaborative nature also encouraged a deliberate, abbreviated "community of practice" 35 wherein the cooperative learning and knowledge sharing that took place were of benefit to all parties. Exchanges were not simply clinician-to-researcher; mutual sharing of knowledge and expertise was encouraged regardless of individuals' roles on the coding team.

This group coding process of simulation video data by researchers and clinicians may be applicable to further research that seeks to derive and/or refine competencies in other areas of healthcare. As this study generated descriptive language of competencies for single session allied healthcare from the experience of a small number of social workers, further validation of the themes presented here could be accomplished via group coding of simulation video data of a single session from the perspective of other allied health professions. Comparing such findings between fields and practice contexts could result in a more robust framework of competencies.

\section{Implications for Allied Health Education}

Advanced and specific clinical practice competencies, such as the single-session focus in this article, can be used to guide education programs to assess student competencies as well as adherence to accreditation standards in allied health disciplines. ${ }^{12,21,36}$ Given the increasing importance of coordinated and collaborative care across health disciplines, a multidisciplinary approach that highlights identified common skills, such as those described in this study, to the delivery of allied health services for individual patients and specific populations is warranted. ${ }^{37}$ Further, the inclusion of data culled from simulation-based learning strategies can contribute to the development of student competence given the widespread integration of these educational approaches in many multidisciplinary team settings. Such initiatives have facilitated integration of diverse curricula and competencies (eg, communication skills, decision-making, complex emergency response) into health education. ${ }^{9,38}$ This study adds to the existing research and practice guidance on allied health competencies by focusing specifically on health practice environments and single-session practice.

The thematic framework emerging from this study of the critical competencies required for a single session in health social work further develops the research on singlesession practice by articulating the important skills to be employed during the three progressive phases of joining, working, and ending. Based on the 32 simulation videos analyzed, the coding team's decades of health practice experience, and extant literature on single-session healthcare, ${ }^{18,39}$ these findings may be typical of competencies required for single-session healthcare. Prior research found that single-session practice may be considered the pinnacle of clinical expertise and skill because of the rapidity of engagement and information transfer required. $^{39}$ In such clinical interactions, the clinician needs to incorporate assessment, case management, and/ or treatment into the single session. Patients have recalled that the key skills of single-session healthcare included confidence, empathy, and knowledge ${ }^{18}$ which were also reflected in the themes in the "ongoing" category of the 
thematic competency framework developed in this study: (1) use of self; and (2) scope of practice. Given the recommendation that single-session practice needs further exploration and legitimation in allied health, ${ }^{39}$ research should explore the development of an evaluative tool focused on the competencies of single-session practice in allied health that could be utilized to train students in interprofessional health education.

\section{Limitations}

While based on a real-life practice scenario, ${ }^{12}$ the simulation videos were drawn from one advanced practice in health course in a social work program. This limits the applicability of the findings. However, the findings align with emerging research in allied healthcare, ${ }^{18,39}$ suggesting that further testing of the framework may validate its findings across contexts and settings. Variability may exist related to the quality of instruction and preparation for the simulation scenario, the level of student anxiety and motivation, and the actors' performance. There is a risk of confirmation bias as the clinicians on the coding team were recruited through the principal investigator and university network. However, the principal investigator had only met one of the expert clinician coders prior to study participation. Further, the clinician coders did not know one another, nor did they know the simulation participants or actors. The clinicians on the coding team, albeit very experienced professionals, particularly represented social work and thus cannot be considered representative of all allied health professions.

\section{Conclusion}

The single-session competency themes that emerged from the PBR group coding method utilized during this study are rooted in contemporary healthcare practice, including the phases of joining, working and ending. The simulations were deemed by the expert clinicians to be an accurate depiction of a single-session clinical consultation, and the recordings provided a tangible method of identifying and understanding the importance of critical skills and competencies. The results of this study provide guidance to clinicians and students working in allied health settings and utilizing single-session clinical interactions.

\section{Disclosure}

The authors report no conflict of interest in this work.

\section{References}

1. Pawson R, Boaz A, Grayson L, Long A, Barnes C. Knowledge review 3: types and quality of knowledge in social care. 2003. Available from: http://www.scie.org.uk/publications. Accessed September 12, 2020.

2. Paans W, Wijjkamp I, Wiltens E, Wolvensberger MV. What constitutes an excellent allied health care professional? A multidisciplinary focus group study. $J$ Multidiscip Healthc. 2013;6:347-356. doi:10.2147/JMDH.S46784

3. Pockett R, Dzidowska M, Hobbs K. Social work intervention research with adult cancer patients: a literature review and reflection on knowledge-building for practice. Soci Work Health Care. 2015;54 (7):582-614. doi:10.1080/00981389.2015.1046577

4. Drisko J. Research evidence and social work practice: the place of evidence-based practice. Clin Soc Work J. 2014;42(2):123-133. doi: 10.1007/s10615-013-0459-9

5. Jaynes S. Using principles of practice-based research to teach evidence-based practice in social work. J Evid Base Soc Work. 2014;11 (1-2):222-235. doi:10.1080/15433714.2013.850327

6. Sackett DL, Rosenberg W, Gray J, Haynes RB, Richardson WS. Evidence based medicine: what it is and what it isn't. BMJ. 1996;312(7023):71-72. doi:10.1136/bmj.312.7023.71

7. Epstein I. Reconciling evidence-based practice, evidence-informed practice, and practice-based research: the role of clinical data-mining. Soc Work. 2011;56(3):284-288. doi:10.1093/sw/56.3.284

8. Yong LMO, Lim ELP, Khoo ORL, Goh SC. Implementing competency-based medical social work education and training in an academic medicine center in Singapore. Hum Serv Organ Manag Leadersh Gov. 2014;38(5):459-470. doi:10.1080/23303131.2014.899

9. Bogo M, Rawlings M, Katz E, Logie C. Using Simulation in Assessment and Teaching. Alexandria, VA: Council on Social Work Education; 2014.

10. Vass A. Introduction: the quest for quality. In: Vass A, editor. Social Work Competences: Core Knowledge, Values and Skills. London, UK: Sage; 1996: 1-7.

11. Canadian Centre on Substance Abuse. Competencies for Canada's substance abuse workforce. Available from: https://www.ccsa.ca/ sites/default/files/2019-05/CCSA-Workforce-BehaviouralCompetencies-Report-2014-en.pdf. Accessed September 12, 2020.

12. Craig SL, McInroy LB, Bogo M, Thompson M. Enhancing competence in health social work education through simulation-based learning: strategies from a case study of a family session. J Soc Work Educ. 2017;53(1):S47-S58. doi:10.1080/10437797.2017.1288597

13. Craig SL, McInroy LB, Goulden A, et al. The health social work competency rating scale: development of a tool for education and practice. Soc Work Educ Int J. 2020:1-14. doi:10.1080/ 02615479.2020 .1768233

14. Vitali S. The acquisition of professional social work competencies. Soc Work Educ. 2011;30(2):236-246. doi:10.1080/02615479.2011.540400

15. Ducat W, Kumar S. A systematic review of professional supervision experiences and effects for allied health practitioners working in nonmetropolitan health care settings. J Multidiscip Healthc. 2015;8:397407. doi:10.2147/JMDH.S84557

16. Bosma H, Johnston M, Cadell S, et al. Creating social work competencies for practice in hospice palliative care. Palliat Med. 2010;24 (1):79-87. doi:10.1177/0269216309346596

17. Hymmen P, Stalker CA, Cait C. The case for single-session therapy: does the empirical evidence support the increased prevalence of this service delivery model? J Ment Health. 2013;22(1):60-71. doi:10.3109/09638237.2012.670880

18. Ewan V, Mushquash AR, Mushquash CJ, Bailey K, Haggarty JM, Stones MJ. Single-session therapy in outpatient mental health services: examining the effect on mental health symptoms and functioning. Soc Work Ment Health. 2018;16(5):573-589. doi:10.1080/ 15332985.2018.1456503 
19. Council on Social Work Education. Integrated health social work field placement project: social work core competencies \& integrated healthcare. 2013. Available from: https://www.cswe.org/getattach ment/Centers-Initiatives/Institutional-Research/Social-Work-andIntegrated-Behavioral-Healthcare-P/Learning-Network-Resources/ Webinar-1-CoreCompetencies.pdf.aspx. Accessed September 12, 2020.

20. McAlinden F, McDermott F, Morris J. Complex patients: social workers' perceptions of complexity in health and rehabilitation services. Soc Work Health Care. 2013;52(10):899-912. doi:10.1080/ 00981389.2013.834032

21. Kourgiantakis T, Bogo M, Sewell KM. Practice Fridays: using simulation to develop holistic competence. J Soc Work Educ. 2019;55 (3):551-564. doi:10.1080/10437797.2018.1548989

22. Kourgiantakis T, Sewell KM, Bogo M. The importance of feedback in preparing social work students for field education. Clin Soc Work J. 2018;47:124-133. doi:10.1007/s10615-018-0671-8

23. Kourgiantakis T, Sewell KM, Hu R, Logan J, Bogo M. Simulation in social work education: a scoping review. Res Soc Work Prac. 2019;30 (4):433-450. doi:10.1177/1049731519885015

24. Couturier Y, Gagnon D, Carrier S, Etheridge F. The interdisciplinary condition of work in relational professions of the health and social care field: a theoretical standpoint. J Interprof Care. 2008;22(4):341351. doi:10.1080/13561820802190616

25. Bogo M. Field instruction in social work: a review of the research literature. In: Shulman L, Sayfer A, editors. Supervision in Counseling: Interdisciplinary Issues and Research. New York, NY: Haworth; 2005: 49-68.

26. Mooradian J. Using simulated sessions to enhance clinical social work education. J Soc Work Educ. 2008;44(3):21-33. doi:10.5175/ JSWE.2008.200700026

27. Keskitalo T, Ruokamo H, Gaba D. Towards meaningful simulationbased learning with medical students and junior physicians. Med Teach. 2014;36(3):230-239. doi:10.3109/0142159X.2013.853116

28. Goldman R, Pea R, Barron B, Derry SJ. Preface. In: Goldman R, Pea $\mathrm{R}$, Barron B, Derry SJ, editors. Video Research in the Learning Sciences. New York, NY: Routledge; 2014: ix.
29. Eaton AD. Filmed simulation to train peer researchers in communitybased participatory research. Soc Work Res. 2019;43(3):195-199.

30. Friend J, Militello M. Lights, camera, action: advancing learning, research, and program evaluation through video production in educational leadership preparation. J Res Leadersh Educ. 2014;10(2):81103. doi: $10.1177 / 1942775114561120$

31. Birks M, Mills J. Grounded Theory: A Practical Guide. Thousand Oaks, CA: Sage; 2015.

32. Charmaz K. Constructing Grounded Theory. Thousand Oaks, CA: Sage; 2014.

33. Bogo M. Social Work Practice: Concepts, Processes, and Interviewing. New York, NY: Columbia University Press; 2006.

34. International Federation of Social Workers. Global standards. 2012. Available from: http://ifsw.org/policies/global-standards/. Accessed September 12, 2020.

35. Singer JB, Gray SW, Miehls D. An educator's guide to the development of advanced practice competencies in clinical social work. $J$ Teach Soc Work. 2012;32(5):451-470. doi:10.1080/08841233. 2012.726206

36. Chouvarda IG, Goulis DG, Lambrinoudaki I, Maglaveras N. Connected health and integrated care: toward new models for chronic disease management. Maturitas. 2015;82:22-27. doi:10.1016/j. maturitas.2015.03.015

37. Cooper S, Cant R, Porter J, et al. Simulation based learning in midwifery education: a systematic review. Women Birth. 2012;25 (2):64-78. doi:10.1016/j.wombi.2011.03.004

38. Gibbons J, Plath D. Single session social work in hospitals. Aust $N Z$ J Fam Ther. 2012;33(1):39-53. doi:10.1017/aft.2012.5

39. Wenger E. Communities of practice: a brief introduction. 2011. Available from: https://scholarsbank.uoregon.edu/xmlui/bitstream/handle/1794/ $11736 / \mathrm{A} \% 20 \mathrm{brief} \% 20$ introduction $\% 20$ to $\% 20 \mathrm{CoP}$.pdf? sequence $\%$ E2\% $80 \% \mathrm{~B} 0=\% \mathrm{E} 2 \% 80 \% \mathrm{~B} 01$. Accessed September 12, 2020.
Journal of Multidisciplinary Healthcare

\section{Publish your work in this journal}

The Journal of Multidisciplinary Healthcare is an international, peerreviewed open-access journal that aims to represent and publish research in healthcare areas delivered by practitioners of different disciplines. This includes studies and reviews conducted by multidisciplinary teams as well as research which evaluates the results or conduct of such teams or healthcare processes in general. The journal covers a very wide range of areas and welcomes submissions from practitioners at all levels, from all over the world. The manuscript management system is completely online and includes a very quick and fair peer-review system. Visit http://www.dovepress.com/testimonials. php to read real quotes from published authors. 